\title{
CARDIAC OUTPUT IN A CASE OF PERICARDIAL EFFUSION WITH A NOTE ON PERICARDIAL PAIN
}

BY

\author{
C. M. FLETCHER \\ From the Department of Medicine, British Postgraduate Medical School
}

Received May 28, 1945

The mechanism of cardiac failure in pericardial effusion, which is generally accepted, is derived from the classical experiments of Cohnheim (1889) and Starling (1897) on the effects of injection of oil into the pericardial sac in dogs. They showed that at first the venous pressure rose parallel with the increasing intra-pericardial pressure, the arterial pressure remaining unchanged. When higher intrapericardial pressure was induced, it began to approach the venous pressure, and at this stage a progressive fall in arterial pressure began and continued until the circulation ceased. They explained these observations by supposing that blood was dammed back in the venous system so that cardiac output fell, the arterial pressure being at first maintained by arteriolar constriction, but failing when the fall in output became extreme. No actual measurements of cardiac output were made. The expression "cardiac tamponade" is derived from this conception of obstruction of the venous inflow to the heart.

Kuno (1917) showed that there was a fall of cardiac output with increasing intrapericardial pressure in a heart-lung preparation, but his results are not applicable to the intact animal since he maintained the venous pressure at a constant level throughout his experiments.

Very few observations on circulatory dynamics in pericardial effusion in man have been made. Katz and Gauchatz (1924) made a detailed study of the mechanism of pulsus paradoxus, and showed that the waning of the pulse beat was due to defective filling of the heart during inspiration. Burwell and Strayhorn (1932) and Resnik, Friedman, and Harrison (1935) have measured cardiac output by respiratory techniques in patients with concretio cordis: they showed that it is low, and rises after operative release of the heart. These conclusions are not, however, applicable to cases of pericardial effusion. Recently an opportunity arose of studying cardiac output and right auricular pressures by means of the cardiac catheter (McMichael and Sharpey-Schafer, 1944a) with simultaneous measurement of intrapericardial pressure in a case of malignant pericarditis with effusion.

Case History A manageress of a canteen, aged 32, had noticed a painless swelling in the right breast for two years, but had remained in good health till three weeks previously, when she began to become breathless on exertion. During the previous week she had been breathless at rest and her ankles had swollen.

On examination on $24 / 11 / 44$ she was of normal build. She had severe dyspnœa at rest with orthopnœa. She had a carcinoma of the right breast involving the skin, with secondary enlargement of the right axillary glands and œdema of the right arm. The jugular veins were distended up to $3 \mathrm{~cm}$. above the sternal angle. The cardiac impulse was diffuse, with maximal pulsation in the fifth interspace, 4 inches from the midline. The sounds were normal, but loud and soft beats alternated. There was pulsus paradoxus at the wrist. B.P. 122/88. There were scattered rhonchi in both lung fields with signs of effusion at the right base. The liver was enlarged to $4 \mathrm{~cm}$. below the costal margin. There was slight pitting œdema of both ankles.

An X-ray of the chest showed general cardiac enlargement, with opacity of the right costophrenic angle. An electrocardiogram (Fig. 1) showed electrical alternation with inversion of $\mathrm{T}$ in all leads. 

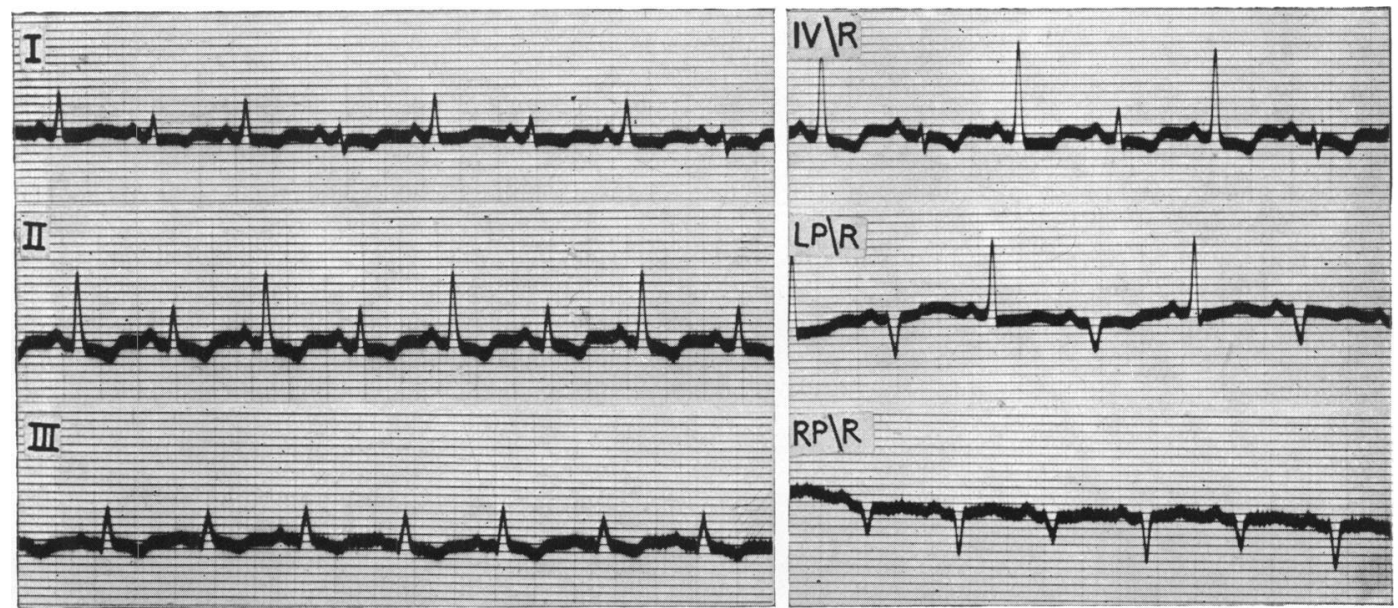

FIG. 1.-Electrocardiogram showing inversion of $\mathrm{T}$ in all leads and electrical alternation.

Blood count: Hb. 101 per cent; Red blood cells 5.3 million; white blood cells 11,000.

The diagnosis was malignant pericarditis with effusion.

On 26/11/44 the jugular veins were distended to the angle of the jaw. The patient developed pain in the left chest and a friction rub was heard. Later she had a small hæmoptysis. Digoxin $1.5 \mathrm{mg}$. was given intravenously. The jugular venous distension fell to a level of $3 \mathrm{~cm}$. above the sternal angle, but there was no clinical improvement.

On 28/11/44, with the patient propped up in bed at an angle of $45^{\circ}$ from the horizontal, a cardiac catheter was passed up the left antecubital vein and its tip was located in the right auricle by X-ray. It was connected with a citrate manometer. The right auricular pressure stood at the high value of $15 \mathrm{~cm}$. above the sternal angle. (Normal about $6 \mathrm{~cm}$. below the sternal angle in this position.) There was slight variation in the pressure during the next 30 minutes, but $15 \mathrm{~cm}$. was the average level. The cardiac output was $4 \cdot 1$ litres a minute, which is a low normal figure. A needle was then inserted into the pericardial sac in the fourth left interspace in the mid-clavicular line and was connected to a citrate manometer. The intrapericardial pressure was $7 \mathrm{~cm}$. above the sternal angle. During the next twenty minutes 100 c.c. of heavily blood-stained fluid was allowed to run out of the pericardial sac. At the end of the period the right auricular pressure had fallen to $9 \mathrm{~cm}$. and the intrapericardial pressure to $2 \mathrm{~cm}$. above the sternal angle. Ten minutes later the cardiac output was 3.95 litres a minute (see Fig. 2). During the period of these observations the pulse rate was 124 a minute. The blood pressure was difficult to estimate owing to the œdema of the right arm. The systolic pressure was $122 \mathrm{~mm}$. The diastolic pressure could not be measured satisfactorily but appeared to be $100 \mathrm{~mm}$. After the pericardial aspiration the patient showed a temporary improvement; but then became more dyspnœic, and died five hours later.

In the course of the experiment an incidental observation was made which is of interest. The citrate solution in the manometer was found to be irritant when it escaped into the subcutaneous tissues during the insertion of the catheter (an acid citrate solution, $p \mathrm{H} .4$, having been used unwittingly). Each time the manometer was attached to the pericardial needle some of this citrate entered the pericardium and on each occasion the patient complained of pain localized to the outer border of the left upper arm.

Post-mortem, the pericardial sac was distended with 500 c.c. heavily blood-stained fluid. There was a miliary dissemination of secondary deposits throughout the body. There was a large secondary deposit at the root of the pulmonary artery involving the pericardium, which was the source of the hæmorrhagic effusion. The myocardium showed no naked eye evidence of secondary deposits. There was bilateral sero-sanguineous pleural effusion and a large infarct in the left lung. 


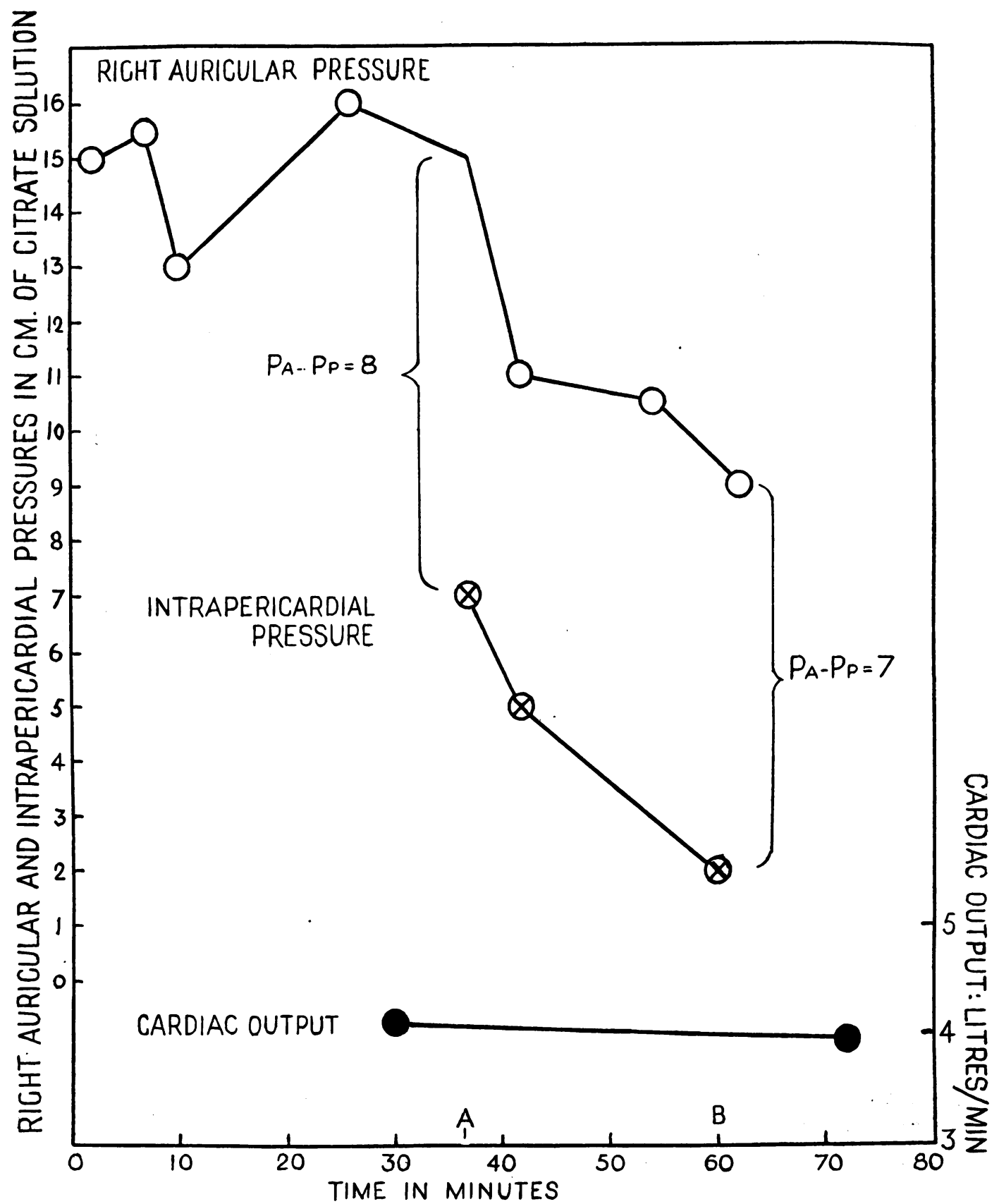

FIG. 2.-Effect of pericardial paracentesis on right auricular and intra-pericardial pressures and on cardiac output. The high right auricular pressure falls as the intrapericardial pressure is lowered by paracentesis. Thus the difference between the two pressures $\left(\mathbf{P}_{a}-\mathbf{P}_{p}\right)$, which represents the filling pressure of the right auricle is not significantly altered. Cardiac output before and after paracentesis is also unaltered. Between $\mathrm{A}$ and $B$ on the base line 100 c.c. of fluid were removed from the pericardial sac.

\section{COMMENT}

One of the most important factors that influence cardiac output is the pressure under which the auricle fills. This filling pressure is the difference between the right auricular pressure and the pressure on the outside of the heart. The normal hydrostatic intra-auricular pressure has been measured by Richards, Cournand, Darling, Gillespie, and Baldwin (1941) in six normal subjects and was found to vary between $+6 \cdot 1$ and $+0.8 \mathrm{~cm}$. of saline with an average of $+3.7 \mathrm{~cm}$. The normal mean intrathoracic pressure is also a variable quantity, 
but probably averages $-6.0 \mathrm{~cm}$. saline $(-4.5 \mathrm{~mm}$. Hg., Best and Taylor, 1943). Thus the normal filling pressure of the right auricle has a wide range, but averages $+9.7 \mathrm{~cm}$. of saline. In this case of pericardial effusion the filling pressure of the right auricle could be derived from the difference between the right auricular pressure and the intrapericardial pressure $\left(\mathrm{P}_{a}-\mathbf{P}_{p}\right)$. Before the pericardial fluid was removed it was $+8 \mathrm{~cm}$. saline, which is a figure well within normal limits (see Fig. 1). After the fluid was removed the filling pressure was practically unaltered, standing at $+7 \mathrm{~cm}$. saline. Associated with this normal and unaltered filling pressure the cardiac output was within normal limits and was also unaltered.

A single observation such as this provides an unsound basis on which to draw any conclusion about the circulatory dynamics in pericardial effusion, but it is interesting to find cardiac output well maintained in a case where the clinical picture was one of cardiac tamponade and to find no alteration in the output when the "tampon" was removed. The output is apparently maintained by the rise of venous pressure, which provides a normal filling pressure for the right auricle. It is clear that any therapeutic measure that may lower the venous pressure, such as venesection or digitalization (McMichael and Sharpey-Schafer, $1944 b$ ) is contra-indicated. In this case digitalization was certainly of no benefit, although it resulted in no obvious harm. With an increasing effusion, the pericardial pressure will eventually begin to approach the venous pressure, as Cohnheim showed. The output will then fall and the circulation will ultimately come to a standstill. This is presumably what happened terminally in this case, since the pericardial sac was distended with blood-stained fluid post-mortem.

\section{SUMMARY}

A case of malignant pericarditis with effusion, presenting the clinical picture of " cardiac tamponade" is described.

Measurements of right auricular and pericardial pressure and cardiac output revealed a right auricular filling pressure and cardiac output within normal limits.

Paracentesis of the pericardium produced a parallel lowering of right auricular and pericardial pressures, so that the right auricular filling pressure remained unaltered. The cardiac output was also unaltered

The suggestion is made that it is only in the agonal stages of cardiac tamponade that the pericardial pressure approaches the venous pressure and that cardiac output begins to fall.

In this case irritation of the pericardium produced pain on the outer border of the left upper arm.

I wish to thank Dr. J. McMichael for his assistance in making these observations.

\section{REFERENCES}

Best, C. H. and Taylor, N. B. (1943). The Physiological Basis of Medical Practice. London: Baillière, Tindall \& Cox.

Burwell, C. S., and Strayhorn, W. D. (1932). Arch. Surg., 24, 106.

Cohnheim, J. (1889). Lectures on General Pathology, Vol. I. London: New Sydenham Society.

Katz, L. N. and Gauchatz, H. W. (1924). Arch. intern. Med., 33, 371.

Kuno, Y. (1917). J. Physiol., 51, 221.

McMichael, J. and Sharpey-Schafer, E. P. (1944a). Brit. Heart J., 6, 33. (1944b). Quart. J. Med., 37, 123.

Resnik, L. H., Friedman, B. and Harrison, T. R. (1935). In Harrison, T. R., Failure of the Circulation. London: Baillière, Tindall \& Cox.

Richards, D. W., Cournand, A., Darling, R. C., Gillespie, W. H. and Baldwin, E. de F. (1942). Amer. J. Physiol., 136, 115.

Starling, E. H. (1897). Lancet, 1, 652. 